\title{
ESCULTURA EN HISPANOAMÉRICA DURANTE EL SIGLO XIX: EL CASO CHILENO*
}

\author{
POR \\ Pedro Emilio Zamorano Pérez \\ Universidad de Talca, Chile
}

Este artículo ilustra acerca del desarrollo de la escultura en Chile durante el siglo XIX y comienzos del $\mathrm{XX}$, aportando antecedentes sobre aquellos modelos, obras y autores de mayor significación y trascendencia. Ilustra sobre el repertorio iconográfico de obras y cómo en ello se traducen representaciones simbólicas vinculadas con la cultura, la historia y la identidad del país. Se entrega información sobre la escultura y su relación con la ciudad y la presencia en ella del monumento público.

Palabras clave: Escultura; Chile; Artistas; Ciudad y monumento público.

NINETEENTH-CENTURY SPANISH AMERICAN SCULPTURE: THE CHILEAN CASE

This article deals with the development of sculpture in Chile during the $19^{\text {th }}$ and early $20^{\text {th }}$ centuries, providing data on those models, art works and sculptors of greatest significance. Emphasis is placed on the iconographic repertory of these works in which symbolic representations related to the culture, history and the identity of the country can be found. The relationship between sculptural works and the city and the presence in it of public monuments is also discussed.

Key words: Sculpture; Chile; Artists; Cities and public monuments.

$\left(^{*}\right)$ Este artículo corresponde al Proyecto de Investigación n. ${ }^{\circ}$ 1085295, Escultura chilena 1854-1960: el trasluz de su identidad, financiado por el Fondo Nacional de Ciencia y Tecnología de Chile (FONDECYT). Investigador responsable: Pedro Emilio Zamorano Pérez. Coinvestigadores: Claudio Cortés López, Universidad de Chile, Francisco Gazitúa Costabal, escultor. Coinvestigador extranjero: Dr. Francisco Portela Sandoval, Catedrático Universidad Complutense de Madrid. Ayudantes: historiadoras Cynthia Valdivieso y Marisol Richter. 


\section{Escultura chilena: una mirada clásica en su origen}

Todas las sociedades a lo largo de la historia han generado imaginarios sociales -especie de representaciones propias- a través de las cuales se designan a sí mismas, estableciendo simbólicamente sus normas y valores. A través de estos imaginarios los distintos grupos culturales han intentado dar respuesta a interrogantes tales como ¿quiénes somos?, ¿qué queremos? y ¿en qué estamos? En otras palabras, han intentado definir su "identidad", es decir, cómo se articula el mundo y sus relaciones con él; sus cosmovisiones, necesidades y deseos. Estos conceptos se hacen visibles y toman cuerpo de muchas formas en la construcción cultural de una sociedad. En los textos escritos, en las costumbres, en los mitos colectivos, en los protocolos, en las modas, entre otros. Se perciben también, de forma muy clara, en sus manifestaciones estéticas visuales; pintura y escultura.

La sociedad chilena decimonónica, contexto y tiempo al que se refieren estas reflexiones, comienza a definir sus modelos simbólicos nacionales en consonancia con la construcción de la República, una vez consolidado el proceso independentista. En estos años iniciales estaba todo por hacerse; por ello resultaba natural recurrir a modelos foráneos. Francia y, en menor medida, otros países tales como España, Italia, Alemania e Inglaterra, pasan a ser ejes en la construcción de la intelectualidad y la cultura nacionales. Surge aquí un primer modelo de representación propia; se trata de la aspiración, especialmente de la elite emergente, de verse en el espejo de la cultura europea. A decir de Bernardo Subercaseuaux "Se hace necesario recurrir a un modelo diferente. El concepto de 'apropiación' más que una idea de dependencia y de dominación exógena apunta a una fertilidad, a un proceso creativo a través del cual se convierten en 'propios' elementos ajenos"1.

Hacia el ecuador del siglo XIX se fundan las academias artísticas en el país ${ }^{2}$. Los primeros directores extranjeros de estos planteles y los modelos y contenidos pedagógicos que se traen al país propician una clara identificación de nuestros procesos estéticos con un paradigma estético e iconográfico europeo.

En el discurso fundacional del primer director de la Academia de Pintura, Alejandro Cicare1li (1808-1879), se plantea una propuesta de desarrollo para el arte nacional. El artista italiano habla allí de los artistas griegos y de los conceptos que desarrollan en sus expresiones estéticas y culturales: construcciones, esculturas y pinturas. La sanción del pintor napolitano, manifestada en el referido documento, de que Chile sería algún día la "Atenas de la América del Sur"3, tenía sentido en una sociedad que buscaba validar su discurso simbólico a través de arquetipos externos. La escultura, al igual que la pintura, se desarrolla una vez institucionalizada su enseñanza en el país. Antes, descontada la imaginería colonial, el registro de obras o autores es relativamente escaso. En el terreno de la escultura decimonónica, en Chile se da un proceso similar al producido en otros países iberoamericanos. Este se caracterizó por un descenso sostenido en la producción de la tradicional escultura religiosa heredada de la Colonia y la introducción y proliferación de la estatuaria conmemorativa, de carácter secular e índole público, vinculada a los proyectos ornamentales de las ciudades.

\footnotetext{
${ }^{1}$ Subercaseaux, Bernardo, Historia de las ideas y de la cultura en Chile, Tomo III, "El Centenario y las Vanguardias", Editorial Universitaria, Santiago de Chile, 2004, p. 25.

${ }^{2}$ La Academia de Pintura fue inaugurada el año 1849, en tanto que la Clase de Escultura el año 1854.

${ }^{3}$ Discurso pronunciando por Alejandro Cicarelli en acto de apertura de la Academia de Pintura. Consignado en Artes Plásticas en los Anales de la Universidad de Chile (Letelier, Rosario, Emilio Morales y Ernesto MuÑoz), publicación del Museo de Arte Contemporáneo, Santiago de Chile, 1993, p. 16.
} 


\section{Inicios de la enseñanza de la escultura en el país}

A escasos años de la fundación de la Academia de Pintura comienza la enseñanza de la escultura. En 1854 fue creada la Escuela de Escultura Ornamental en Relieve. Se trataba de una entidad para formar artesanos, que funcionaba en la Sacristía de la Capilla de la Soledad, contigua al Convento de San Francisco. Su director y maestro inicial fue el escultor francés Augusto Francois (1814-1896), artista del que se poseen pocas noticias biográficas ${ }^{4}$. Un Decreto del Supremo Gobierno, del Departamento de Justicia, Culto e Instrucción Pública, de fecha 24 de mayo de 1854, da inicio y estructura académica a esta actividad en Chile y nombra a su Director 5 .

En una primera etapa, la enseñanza de la pintura y la escultura no tenía un tronco institucional común. Esta situación es modificada el año 1858 a través de un Decreto del 3 de agosto, firmado por el Presidente Manuel Montt y por el Ministro Rafael Sotomayor, en que se reformaba la Academia de Pintura y se le confería a esos estudios un rango universitario. El artículo $1 .^{\circ}$ del referido documento establecía una sección de Bellas Artes en el Departamento Universitario del Instituto Nacional e integraba las especialidades de Pintura y Dibujo Natural, Arquitectura y Escultura. Esta medida, aparte de uniformar la enseñanza de dichas materias, proveía de una estructura académica a dichos estudios. Establecía, también, dos concursos anuales, además de premios y pensiones en el extranjero para los alumnos más meritorios. El 7 de enero de 1859, un nuevo Decreto Supremo reorganizaba en forma más completa la clase de escultura, intentando establecer una mejor armonía entre los aspectos prácticos y teóricos de la disciplina. Se dividen las actividades en dos secciones: estatuaria y ornamental. Bajo este contexto se otorga la oportunidad de impartir la enseñanza de la disciplina en el país bajo una estructura metodológica, con programas de estudio y con el reconocimiento y apoyo del Estado. Saludable fue también la política de enviar a los egresados más meritorios a continuar su formación en el Viejo Continente.

En Chile el arte escultórico se desarrolla durante la primera mitad del siglo XIX en consonancia con la necesidad de exaltar valores independentistas e identitarios. Como no había en el país artistas destacados a quienes poder encargar obras, ni la posibilidad de fundir obras de tamaño mayor, se recurrió a la importación de ellas o a invitar a artistas extranjeros a hacerlas. Uno de los primeros monumentos llegados al país después de la Independencia fue el conjunto escul-

\footnotetext{
${ }^{4}$ En los escasos datos aportados por el Diccionario Benezit, se le señala como discípulo de David d'Angers y de Rude, además de consignar algunas participaciones en los salones de París de 1848 y 1849.

${ }_{5}^{5}$ El documento señala lo siguiente: "Con lo expuesto por el Delegado Universitario en el oficio que precede $\mathrm{i}$ considerando:

1. ${ }^{\circ}$ Que el aprendizaje del dibujo lineal no puede ofrecer todo el provecho de que es susceptible, para los constructores de edificios i ebanistas, como para los que se consagran a otras artes u oficios con que aquel tiene relación, si el artesano no se haya capaz de ejecutar en relieve lo que aprende a dibujar, adquiriendo principios elementales de escultura; i

2. ${ }^{\circ}$ Que don Augusto Francois ha comprobado tener las aptitudes necesarias para la enseñanza de este ramo; vengo a acordar i decreto:

1. ${ }^{\circ}$ Se establece una escuela de escultura ornamental i dibujo de relieve para artesanos. Esta escuela funcionará tres veces por semana i ocupará por ahora el mismo local que la de dibujo lineal de la Cofradía del Santo Sepulcro.

2. $\quad$ Se nombra director de la escuela de escultura a don Augusto Francois con una asignación de seiscientos pesos anuales, que se le abonará por la Tesorería Jeneral desde que principie a funcionar la Escuela.

3. ${ }^{\circ}$ Este establecimiento estará bajo la inspección del Delegado Universitario, quien determinará el tiempo que deban durar las lecciones i lo demás concerniente al régimen de la escuela.

4. ${ }^{\circ} \quad$ Impútese el sueldo decretado a la partida 55 del presupuesto del Ministerio de Justicia i consúltese una cantidad destinada para este objeto en el presupuesto del año entrante.

Refréndese, tómese razón i comuníquese.- MONTT.- Silvestre Ochagavía”.
} 


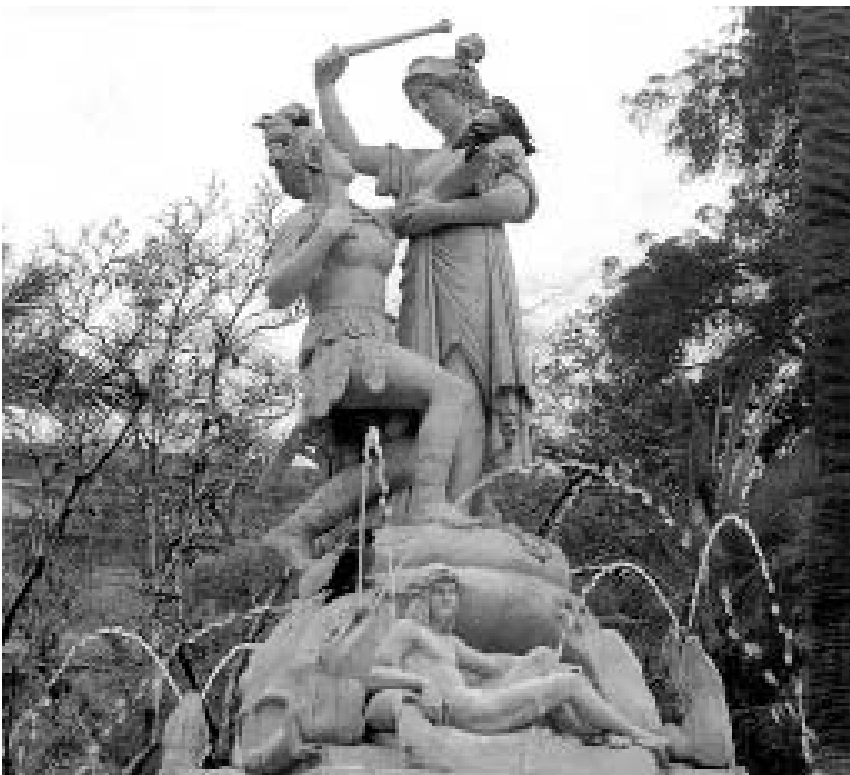

Fig. 1. Francesco Orsolino, "Monumento a la libertad de América", realizado en 1829 e inaugurado en 1836, Plaza de Armas de Santiago de Chile.

tórico "A la libertad de América" (fig. 1), de autoría del artista italiano Francesco Orsolino. Durante la segunda mitad del siglo XIX estos encargos se hacen cada vez más frecuentes. En 1868 se abre en París un concurso para hacer un monumento a Bernardo O'Higgins (fig. 2). El escultor francés Albert Ernest Carrier-Belleuse (18241887) fue el ganador. En la confección de dicha estatua colabora, con toda certeza, Auguste Rodin, quien fuera ayudante del citado artista durante el periodo de creación del monumento. La obra, realizada en 1872, muestra al libertador en un caballo en corbeta, sobre sus enemigos realistas, en el sitio de Rancagua. Carrier-Belleuse es también el autor de dos versiones de la estatua denominada "Víctimas", obra que ilustra el incendio de la iglesia de La Compañía de Jesús, tragedia ocurrida en Santiago el año 1863. El escultor francés Joseph-Louis Daumas (1801-1887), realizó en 1863 una escultura en homenaje a José de San Martín. El también francés Jules-Félix Coutan (1848-1939), primer maestro en París del escultor argentino Rogelio Yrurtia, fue el autor, en 1908, del monumento a Benjamín Vicuña Mackenna, ubicado en la capital chilena. Estas obras ilustran parte de una nómina bastante más extensa.

La clase dirigente del país, el poder político y la opinión pública emergente se constituyen en organizadores y decodificadores del discurso estético nacional. Las voces teóricas, vinculadas ideológica y socialmente con esta elite, adhieren al paradigma académico. Surgen aquí los discursos críticos del escultor José Miguel Blanco -autor de varios escritos-, del pintor Pedro Lira, de Vicente Grez y, en las primeras décadas del siglo pasado, José Miguel Rocuant, José Backhaus, Nathanael Yáñez Silva y Ricardo Richon Brunet. Todos estos actores de la cultura y la institucionalidad del país miran a París como el paradigma a seguir. El paso de los artistas chilenos por la llamada "Ciudad Luz" durante la segunda mitad del siglo XIX significó una vinculación directa con esas fuentes, a la vez que una conexión con un modelo que se extendía, con distinta intensidad y de diversos modos, en el espacio americano.

\section{Estadia de escultores chilenos en París y su conexión con maestros franceses: algunos ejemplos}

Un primer grupo de artistas, a quienes Víctor Carvacho denomina como escultores del "bello estilo"6, comienzan a sentar las bases del desarrollo de la disciplina en el país. Nicanor Plaza,

\footnotetext{
${ }^{6}$ Carvacho, Víctor, Historia de la Escultura Chilena, Editorial Andrés Bello, Santiago de Chile, 1983, p. 187.
} 
José Miguel Blanco y Virginio Arias son los primeros que se encaminan a Europa, a estudiar en las academias tradicionales, bajo un sistema de apoyo generado desde el Estado.

Nicanor Plaza (1844-1918). Muy joven, a los 14 años, ingresó a la clase de escultura dirigida por Francois. En 1863 el artista chileno fue pensionado por el Gobierno para seguir estudios en Europa. En París entra al taller del escultor Francois Jouffroy (1806-1882), artista formado en la École des BeauxArts, pensionado en Roma, vinculado ideológicamente a la tradición neoclásica francesa. Con este maestro, Plaza estudió tres años. En 1866 abrió en la misma ciudad un taller propio, en donde realiza un importante número de obras. De esta época son "Caupolicán" (fig. 3), "El jugador de chueca", "Magdalena", "Amor cautivo", entre otras. Según Vicente Grez, estas obras dieron a Plaza "fama honorable en Francia y popularizaron su nombre en Chile" 1871 el artista fue llamado por el Gobierno chileno para encargarle la clase de escultura que dejaba Francois. Sirvió este cargo por largos años, contándose entre sus discípulos a Virginio Arias, Arturo Blanco, Carlos Lagarrigue, Ernesto Concha, Guillermo Córdova y Simón González. En 1874, habiendo sido comisionado por el gobierno para realizar algunas

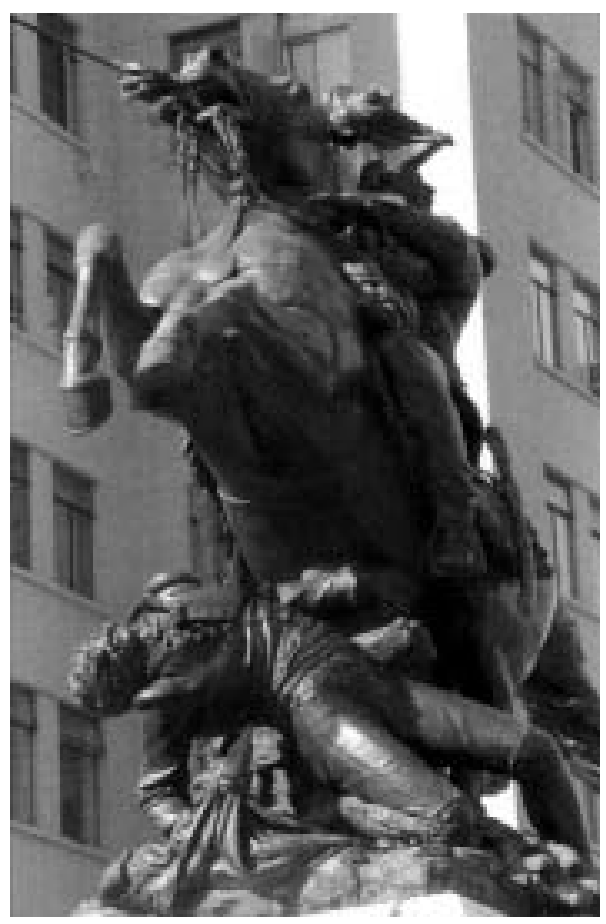

Fig. 2. Albert Ernest Carrier-Belleuse, "Monumento a Bernardo O’Higgins", 1872, Alameda, Santiago de Chile. esculturas en Europa, Plaza se hace acompañar por su discípulo más directo, Virginio Arias. Ese mismo año, la Universidad de Chile le encargó un frontispicio, con alegorías, para el edificio institucional que estaba construyendo. La Guerra del Pacífico inspira algunas obras importantes de este escultor. Destaca aquí un busto de Arturo Prat, esculpido en alabastro, que se encuentra en la Plaza de Iquique. También es importante el grupo escultórico "El soldado chileno no se rinde", que triunfó en la Exposición Universal de París de 1889. Dentro de las muchas otras obras que realiza destacan la escultura de Andrés Bello, emplazada en el edificio corporativo de la Universidad de Chile; también las obras "Prólogo" y "Epílogo", ubicadas en el Teatro Municipal de Santiago de Chile, y "La Quimera" (fig. 4) (Museo Nacional de Bellas Artes de Chile), realizada en 1897, merecedora del Premio de Honor en el Salón de ese año y una Tercera Medalla en la Exposición Internacional de Búffalo, en 1901. A fines de 1900 regresa a Europa. En París instaló su atelier y se consagró a la labor creativa. En sus años postreros y anhelando morir en Italia se establece en Valomdrosa, en los alrededores de Florencia, donde fallece en 1918. Sus restos descansan todavía en esa tierra. La obra general de Plaza, aun cuando tiene cierto débito con el clasicismo postcanoviano, se inserta mejor en los códigos de los escultores romántico-realistas, cuyos exponentes más relevantes de la época fueron David d'Angers (1788-1856) y Antoine Preault (1810-1879). La estadía en Europa de nuestro artista fue bastante prolongada; sumando las distintas etapas en que allí residió es posible concluir que vivió y trabajó en el Viejo Continente por más de cuatro décadas. Su circuito de

\footnotetext{
${ }^{7}$ Grez, Vicente, "Las Bellas Artes en Chile", Catálogo para la Exposición Universal de París, Sección Chilena, 1889.
} 


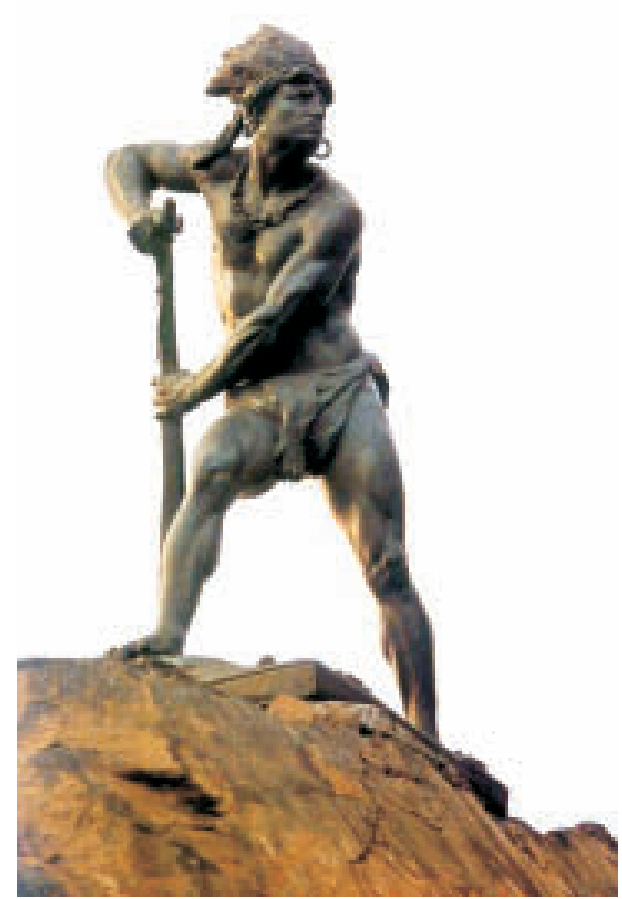

Fig. 3. Nicanor Plaza, “Caupolicán”, 1866, Cerro Santa Lucía, Santiago de Chile.

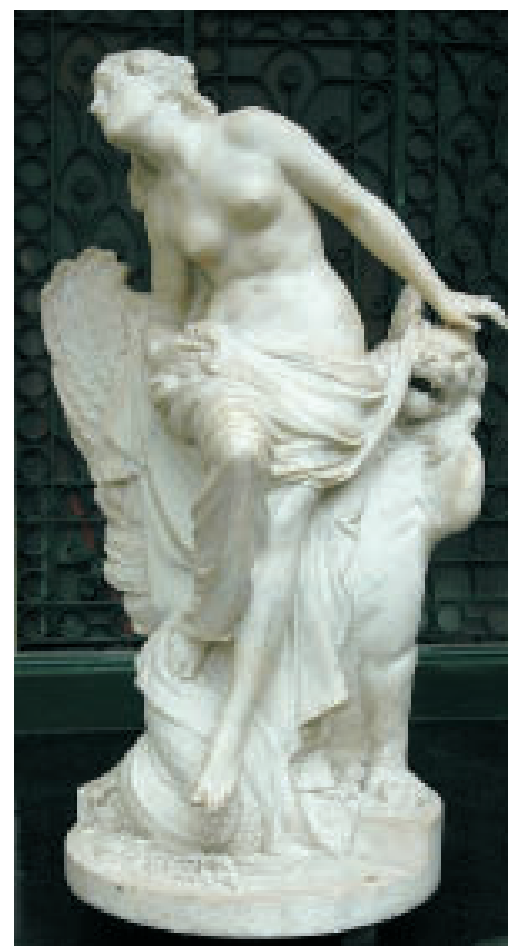

Fig. 4. Nicanor Plaza, "La Quimera", 1897, Museo Nacional de Bellas Artes, Santiago de Chile.

trabajo estuvo en Francia y, ocasionalmente, Italia. En esos lugares pudo conectarse con los escultores europeos más sobresalientes de la época.

José Miguel Blanco ${ }^{8}$. Según Enrique Melcherts ${ }^{9}$, Blanco es, desde el punto de vista cronológico, el primer escultor chileno de la era republicana. En el único documento biográfico suyo, escrito por su hijo Arturo Blanco, se define a este artista como escultor, grabador de medallas y escritor de bellas artes. Iniciado en el mundo del arte por el pintor Juan Bianchi ${ }^{10}$, Blanco se incorpora luego como alumno en la clase de escultura que dictaba por aquella época Augusto Francois. En mayo de 1867, mediante Decreto ${ }^{11}$, el artista fue enviado a París, con el objetivo de estudiar grabado, aplicado al trabajo de monedas. Con tal motivo se embarcó en Valparaíso el 10 de mayo de 1867 con destino a Europa, acompañado de su profesor Francois. Residió en Europa por nueve años. En París inicia sus estudios en el taller de grabado en medallas de Jean Baptiste Faronchon (1812-1871), quien se había destacado como escultor y grabador de medallas, además de haber obtenido el consagratorio Premio Roma, en 1835. Luego de esa experiencia

\footnotetext{
8 José Miguel Blanco nació el 16 de diciembre de 1839. Sus padres fueron don Cruz Blanco, de oficio carpintero, y la señora María Gavilán de Blanco. Falleció en 1897.

9 Melcherts, Enrique, Introducción a la escultura chilena, Impresión en Talleres Ferrand e Hijos Ltda., Valparaíso, Chile, 1982, p. 43.

${ }^{10}$ Pintor italiano llegado a Chile en 1847, a quien se le recuerda como retratista y profesor de Dibujo en el Instituto Nacional.

${ }^{11}$ Decreto N. $^{\circ} 1.218$, de 7 de mayo de 1867. El escultor fue becado a Europa.
} 
inicial el escultor chileno es admitido en la Academia de Bellas Artes de París. En Europa realiza algunas de sus obras más importantes ${ }^{12}$. El 19 de julio de 1870 se inicia la guerra franco-prusiana y el 18 de marzo de 1871 estalla la revolución de La Comuna de París, llenándose la ciudad de conflictos y barricadas. En una carta que envía a su familia (1. ${ }^{\circ}$ de agosto de 1870) Blanco manifiesta sus aprehensiones ante la conflagración. "Usted ya sabrá que la Francia está en guerra con la Prusia, i según se dice la guerra será terrible porque una i otra nación estaban preparándose desde hace mucho tiempo. Nuestro Chile debe contarse muy feliz de no tener guerra como estas grandes naciones, cuya gloria consiste en inventar máquinas para matarse unos a otros... Es muy triste, padre, ver todos los días salir nuevas tropas i en ellas a muchos jóvenes conocidos, alumnos de la escuela, sobre todo" ${ }^{13}$. En otra misiva del $1 .^{\circ}$ de septiembre de ese año el escultor manifiesta todavía una mayor desazón: "Querido padre, la Francia, hoy día, no es la Francia de ayer. Esta maldita guerra ha trastornado al país completamente... En el momento que le escribo, está decidiéndose la suerte de este país o de la Prusia, en la frontera que separa a la Francia de la Bélgica. El combate según los diarios ha comenzado ayer; figúrese cuanta gente habrá muerto hasta el momento. Si la Francia pierde esta batalla, los prusianos se ponen en marcha para París i aquí se han tomado todas las precauciones para defenderse". Estos episodios alteran la vida del escultor y junto a muchos otros artistas, entre ellos Augusto Rodin, emigran a Bruselas, Bélgica, permaneciendo allí largo tiempo. Regresa a París en 1871 y desde allí viaja a distintas ciudades europeas. A comienzos de diciembre se traslada a Roma, ciudad en la que reside hasta mediados de 1873. Allí tuvo contactos estrechos con la Academia Francesa de Bellas Artes en Roma, situada en el Monte Pincio. En el lugar se encontró con algunos de sus condiscípulos con los cuales había compartido en París. Entre ellos los maestros Jean Antoine Injalbert (1845-1933) -maestro también del escultor chileno Simón González- y Jules Félix Coutan. De vuelta en París se prepara para regresar a Chile, emprendiendo el viaje de retorno a principios de noviembre de 1875. Llega a Valparaíso premunido de algunas de sus obras originales, de dibujos y libros de arte, además de muchas reproducciones en yeso. El Gobierno, que le había ofrecido un puesto de grabador en la casa de Moneda, no cumplió lo prometido. Según su hijo Arturo Blanco, "tuvo que luchar toda su vida, como escultor, en un país como este, sin ningún sueldo fiscal i sin bien algunos de fortuna"14. Todos los otros maestros, antes y después de él (Nicanor Plaza, Virginio Arias, Simón González y Carlos Lagarrigue), contaron con una cátedra de escultura en la Escuela de Bellas Artes que les permitió subsistir sin mayores apremios económicos. Otra de las facetas que este artista cultivó estuvo relacionada con la crítica y la historia del arte. Escribió varios textos sobre diferentes temas del acontecer estético y cultural. En 1885 había fundado "Las Veladas Literarias". Posteriormente crea el periódico artístico "San Lunes" y luego funda una publicación de Bellas Artes y Literatura denominada "El Taller Ilustrado". En 1879 presentó al Consejo de la Universidad de Chile un proyecto para la creación de un Museo de Bellas Artes. Su hijo Arturo Blanco, analizando este hecho, refiere el siguiente comentario: "A cargo de ese Museo, o más bien dicho, como Director, quedó Mochi; como portero Pedro Ruiz, i Blanco, como simple espectador. No alcanzó a ser siquiera portero de la obra que él había formado..."15. En 1891, por motivos políticos según se dice, fue separado de su cargo de Secretario del Consejo de Bellas Artes. En 1895 viaja nuevamente a Europa, en busca de salud. "Mi deseo de ver a

\footnotetext{
12 Entre las obras más conocidas que realizó están la "Alegoría a Cuba", "El Padre Las Casas amamantado por una india" y la estatua a "Galvarino".

13 Blanco, Arturo, Cartas del escultor José Miguel Blanco, Santiago de Chile, Imprenta Las Artes Mecánicas, 1907 , p. 35

${ }^{14}$ Blanco, Arturo, Biografía del escultor José Miguel Blanco, Imprenta Cervantes, Santiago de Chile, 1912, p. 15.

15 Op. cit., p. 18.
}

Arch. esp. arte, LXXXIV, 333, ENERO-MARZO 2011, 25-40, ISSN: 0004-0428 


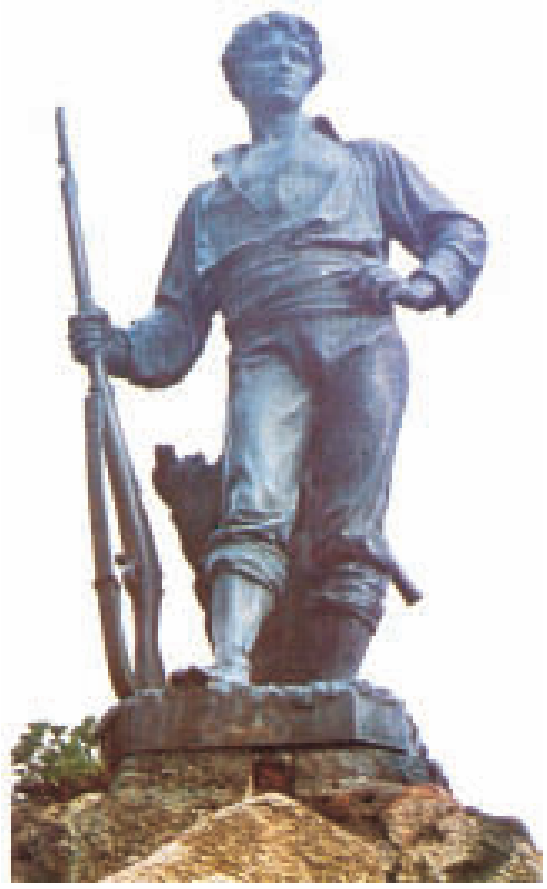

Fig. 5. Virginio Arias, "El roto chileno", 1888, Plaza Yungay, Santiago de Chile.

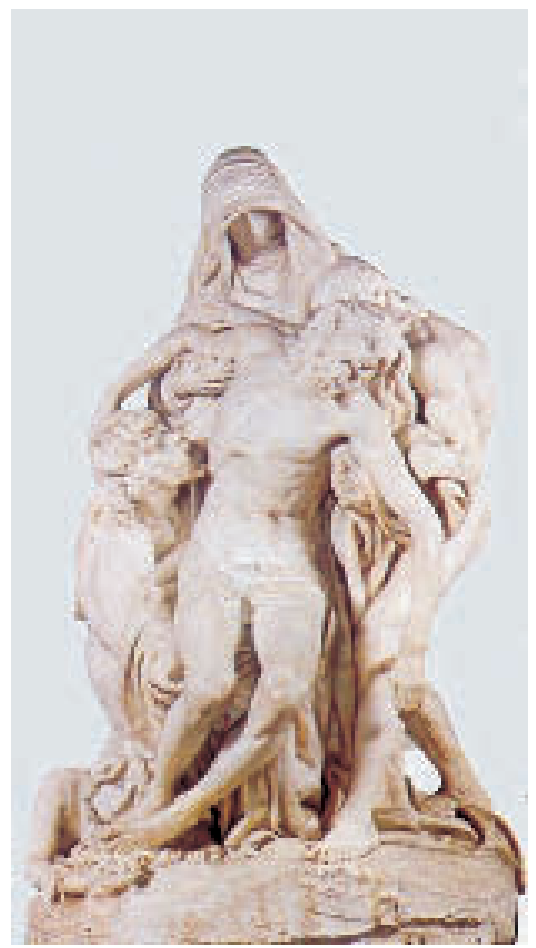

Fig. 6. Virginio Arias,

"El descendimiento de la cruz", 1887, Museo Nacional de Bellas Artes, Santiago de Chile.

París era dictado por la esperanza de mejoría, pero no para morir lejos de mi Patria”, señala en una de sus últimas cartas. Regresa luego a Chile en donde fallece el 4 de febrero de 1897.

Virginio Arias (1855-1941). Este artista vivió y trabajó veintiséis años en París, desde 1874 a 1900. Fue el más destacado alumno de Nicanor Plaza, maestro que lo lleva a la Ciudad Luz a su propio costo. En 1875 es admitido en el Salón de París con una cabeza, un retrato de su maestro Plaza. Al final de ese año, cuando Plaza regresa a Chile, se incorpora como ayudante de Francois Jouffroy, uno de los escultores más exitosos de la época y maestro de su amigo Plaza en la Grande École. Complementa sus ingresos trabajando de santero en una fábrica de estatuas religiosas. En 1879, en los inicios de la guerra del Pacífico entre Chile, Perú y Bolivia, y con serios problemas económicos, intenta regresar al país. Con más urgencias que hacienda decide, finalmente, quedarse en París, incorporándose como alumno a L'École de Beaux Arts (Grande École). Por esta época comienza a trabajar en su escultura "Combatiente del Pacífico" (fig. 5), que devino después en el conocido "Roto chileno". Más tarde ingresó al taller de Jouffroy, en la Escuela de Artes Decorativas (Petit École), en donde tiene como maestro a Alexandre Falguiére (1831-1900). Estudia, además, en la Escuela del pintor y escultor Jean Paul Laurens (1838$1921)^{16}$, artista muy vinculado con Augusto Rodin. Por este vínculo, se sabe de varias situaciones

${ }^{16}$ Jean Paul Laurens fue gran amigo y defensor de Rodin, trabajó como su ayudante. Estando con él estalla el escándalo donde se acusa a Rodin de copiar del natural (vaciado en yeso directo desde un cuerpo humano, no de 
que relacionan a Arias con el autor de "Los burgueses de Calais"17. El trabajo más importante realizado en esta época por Arias es, sin dudas, "El roto chileno", escultura instalada hasta hoy sobre una base de "pesadilla"; una gruta de ferrocemento, imitación piedra, en la Plaza Yungay de Santiago. La escultura tiene cierto débito formal con la obra "Adonis", atribuido a Praxíteles, escultor griego (siglo IV a.C.), obra que se exhibe desde 1543 y hasta hoy en el patio del Belvedere, en el Museo del Vaticano. Arias ganó algunas medallas en París con otra de sus obras más significativas; se trata de "El Descendimiento" (fig. 6), su gran pietá de mármol expuesta actualmente en el Museo de Bellas Artes de Santiago, y que fue exhibida en la Exposición Universal de París, en el pabellón chileno. En sus años parisinos Arias logró una cantidad importante de reconocimientos: medallas de oro y menciones honrosas. A ningún escultor chileno le fue tan bien en París; le fue mejor que su vecino de taller y bien conocido amigo Rodin, diez años mayor que él y que fue rechazado en la Grande École y que nunca ganó medalla de oro alguna en esos salones.

\section{Otros escultores chilenos en París}

Carlos Lagarrigue (1858-1928). Discípulo de Nicanor Plaza, estuvo entre 1877 y 1891 radicado en la Ciudad Luz. En la Petit École, sus profesores fueron Aimé Millet (1819-1891), Jules Dalou (1838-1902) y Charles Gauthier (1831-1891). En Roma tiene un contacto muy próximo con Giulio Monteverde (1837-1917), maestro años más tarde de la destacada escultora chilena Rebeca Matte, y también con Dalou, este último profesor de Maillol y Bourdelle. Guillermo Córdova (1869-1936). En 1886 se incorpora al curso de escultura que impartía Plaza, para luego seguir el derrotero de la mayoría: París. Su estadía de perfeccionamiento en Europa fue de casi veinte años, entre 1892 y 1909. Estudia allí con Jean Antoine Injalbert. Sus obras más representativas fueron "La alegoría de las Bellas Artes", un relieve ubicado en el frontón de acceso al Museo de Bellas Artes de Santiago, y el "Monumento de la Colonia Francesa". Ambas obras, realizadas en 1910, expresan un claro trasfondo alegórico clasicista, muy al tono de la estatuaria académica francesa de la época. Simón González Escobar (1859-1919) cursa también estudios iniciales con Nicanor Plaza. En 1889 viaja a París a perfeccionar sus estudios. Permanece dieciséis años en Europa, recibiendo enseñanzas de los maestros Injalbert, Falguiére y Denis Puech (1854-1942). Su obra decanta hacia un realismo anclado en la cotidianidad. Una de sus obras principales, "El mendigo", obtuvo Medalla de Oro el año 1891 en el Salón Ofícial de Bellas Artes de la capital francesa. Capítulo aparte merece Rebeca Matte (1875-1929), cuya trayectoria y gravitación intelectual se contextualiza más en las décadas iniciales de la pasada centuria. Ella permanece en Europa prácticamente toda su vida de escultora. Sus maestros fueron Puech (discípulo de Jouffroy y Falguiere) y Monteverde (autor del monumento a Vittorio Emanuele). Su actividad docente la desarrolla en la Academia de Bellas Artes de Florencia donde es nombrada profesora.

\footnotetext{
un original escultórico) con la escultura "La Edad de Bronce". Rodin es defendido públicamente por el maestro Laurens.

${ }^{17}$ Don Virginio ve trasladarse en esa misma época a Rodin al "Taller J" del Depósito de Mármoles, el taller vecino de Laurens. Entre 1880 y 1886 está cercano a Rodin. Observa el desarrollo de dos de sus grandes obras: "Las Puertas del Infierno" y, entre 1884 y 1890, observa la creación de "Los burgueses de Calais". Desde 1883 ve entrar a Camile Claudel todos los días al taller del maestro y conoce también a madame De Morla de Vicuña, quien encargó su retrato en mármol que hoy se exhibe en el Museo Rodin. Tiene contactos también con Antoine Bourdelle, quien sería más tarde ayudante de Rodin y, treinta años más tarde, profesor de la mayoría de sus discípulos, profesores de la Facultad de Bellas Artes de Santiago de Chile. Después de esta permanencia de taller contiguo, no cabe dudas que Arias conoció con profundidad la obra y la manera de trabajar del maestro Rodin.
} 
Se hace hincapié en las largas estadías de estos escultores en Europa. La vinculación de estos artistas con el mundo artístico europeo es mucho más profunda y extensa de aquello que podría ser entendido como un simple viaje de perfeccionamiento. Se trata de escultores que llegaron a formar parte de un conglomerado-familia de escultores (maestros y alumnos-escultores y ayudantes) cuyo centro en esa época -siglo XIX y principios del XX- estaba en París. Esta conexión de conocimiento personal, de maestro y alumno, se mantiene hasta la generación de Lily Garafulic (1915), y tiene importantes consecuencias en la práctica y docencia de la escultura en Chile.

\section{La escultura y su relación con la ciudad: el monumento público}

En la producción de esculturas en Chile durante la segunda mitad del siglo XIX se dan situaciones variadas. Encontramos obras realizadas por algunos maestros extranjeros; otras fueron hechas por artistas nacionales en el país o durante sus dilatadas estadías de perfeccionamiento en el extranjero. Los salones de arte también generaron un espacio de demanda y de circulación de obras escultóricas. Además encontramos una cantidad significativa de obras hechas por las fundiciones de arte francesas. A este respecto, Elisabeth Robert-Dehault ${ }^{18}$ habla de más de 200 obras registradas en el país y que fueron realizadas por algunas de las fundiciones más importantes de la época, entre ellas las conocidas Val D'osne-André, Barbezat, Gourmet-Houille, DurenneGHM, Denonvilliers, Thiriot y Capitain-Gény. Dentro de este heterogéneo panorama destaca el monumento público, expresión artística que ocupa un lugar de privilegio en la estatuaria asociada a la ciudad americana decimonónica. La transformación y desarrollo estético de las ciudades en esta parte del mundo se hace evidente luego de establecidos los procesos independentistas. Se construyen edificios públicos y se trazan parques y avenidas, dotándose a muchos de estos lugares de una estatuaria monumental semejante a la europea. Al respecto, Luisa Flora Voionmaa Tanner ${ }^{19}$ señala: "Conscientes de la importancia de crear nuevos espacios representativos y simbólicos, varios gobernantes del siglo XIX asumieron el desafío de intervenir y de transformar la faz de las capitales de Sudamérica”. Estas intervenciones y monumentos responden, las más de las veces, a necesidades políticas de legitimación de los nuevos gobiernos una vez consolidados sus procesos de emancipación. A decir de Gutiérrez Viñuales el monumento público "Ayudó a la urbanización, fue símbolo de adelanto cultural, promovió a los próceres a quienes había que imitar y expresó emblemáticamente la obra pública del gobierno"20. Una especie de "altar laico", como expresara Carlos Reyero ${ }^{21}$. Los ejes, avenidas y plazas de la ciudad fueron lugares apropiados para la instalación de estos monumentos escultóricos. A modo de ejemplo, en México el Paseo de la Reforma fue un lugar de concentración de obras; en Santiago fue la Alameda de las Delicias $^{22}$. El monumento público está destinado a hacer visible y grabar en la memoria colecti-

18 Robert-Dehault, Elisabeth y otros, Arte de fundición francesa en Chile, Ilustre Municipalidad de Santiago de Chile, Talleres Andros Productora, Santiago, 2005, p. 28.

19 VoionmaA TANner, Luisa Flora, Escultura pública: del monumento conmemorativo a la escultura urbana, Santiago 1792-2004, Ocho Libro Editores, Santiago de Chile, 2004, p. 73.

20 Gutiérrez Viñuales, Rodrigo, Monumento conmemorativo y espacio público en Iberoamérica, Cuadernos Cátedra, Madrid, 2004, p. 57.

21 ReYero, Carlos, La escultura conmemorativa en España. La edad de oro del monumento público, 1820-1914, Ediciones Cátedra, Madrid, 1999, p. 375.

${ }^{22}$ Debemos señalar que el desarrollo estatuario más importante de la ciudad de Santiago coincide con la gestión de Intendente que realizara, entre 1872 y 1875, Benjamín Vicuña Mackenna. Algunos comparan la transformación de la ciudad con el trabajo realizado en París, hacia 1850, por el Barón George Eugéne Haussmann. En sus tres años de gestión Vicuña Mackenna intentó dar realidad a su sueño de transformar a Santiago en "la París de América". Su pre- 
va acciones sobresalientes, realizadas generalmente por "héroes locales" en el plano militar, intelectual o valórico. Si bien es cierto que en estas obras se impone por sí mismo el peso del contenido, la estructura formal, los elementos puramente estéticos, constituye también parte relevante de su discurso simbólico. A este respecto el escultor español Pablo Serrano decía que el monumento público incorpora una doble vertiente "el recuerdo de un personaje (o acontecimiento) y la huella de quien lo realiza" ${ }^{23}$ : el artista. La tipología del monumento público es extensa. Las columnas y los obeliscos, a modo de ejemplo, constituyen una referencia clásica por excelencia. En América estos motivos han sido apropiados para conmemorar la Independencia de los distintos países, simbolizando ideas republicanas, asociadas a la firmeza y la perdurabilidad del poder. Estas formas aparecen frecuentemente coronadas con figuras alegóricas que aluden a la libertad, la victoria (Niké helenas), también águilas o cóndores. Además es usual encontrar vinculado a estas ideas el uso de arcos conmemorativos.

Francisco Portela ${ }^{24}$ desarrolla una tipología de la estatuaria pública. Habla del busto, la lápi$\mathrm{da}^{25}$, las estatuas y los grupos escultóricos. Entre los tipos más usados de estatuas menciona las representaciones con figuras en pie, la sedente y la estatua ecuestre. Este último tipo escultórico ha tenido un uso emblemático en América latina. Se le atribuye una vinculación simbólica con la imagen del poder. Antonio Gaya Nuño habla de "La íntima compenetración (del jinete) con su cabalgadura, formando uno y otro una identidad indisoluble, señaladamente jerárquica, poco menos que mitológica. Y entidad única; el caballero ha de ser un solo, bien apartado de la masa, la plebe y la infantería, puesto que en él se honran al capitán, al césar, al héroe"26. Muchos fueron los militares, principalmente asociados a la gesta independentista, que fueron representados a través de esta tipología. En Chile encontramos numerosas obras de esta clase que exaltan las figuras históricas de Bernardo O’Higgins, Manuel Rodríguez, José Miguel Carrera, entre otros.

\section{Otros repertorios temáticos}

Muchos otros temas y personajes registra el arte estatuario de aquella época: los reyes españoles, episodios vinculados al descubrimiento y la figura de Cristóbal Colón han sido temáticas recurrentes. Destaca aquí el Monumento a Hernando de Magallanes (fig. 7), realizado por Guillermo Córdova en 1920 y que se ubica en la ciudad de Punta Arenas.

Se han realizado, también, muchas obras que rinden tributo a conquistadores y fundadores españoles. Los homenajes a Hernán Cortés o Francisco Pizarro, entre otros, fueron abundantes en varias ciudades del continente. Muchos otros temas fueron representados a través de las esculturas emplazadas en plazas y avenidas; héroes castrenses, personajes destacados del mundo civil, conmemoraciones, episodios militares gloriosos, alegorías, deidades del mundo heleno, entre otras representaciones. A través de estas testificaciones iconográficas se va modelando un

ocupación por el arte y la ciudad se pueden traducir en tres aspectos: los monumentos conmemorativos emplazados en la ciudad, las tres exposiciones nacionales organizadas durante su mandato y la estatuaria y desarrollo artístico del cerro Santa Lucía.

${ }^{23}$ Pablo Serrano, citado por Portela Sandoval, Francisco, La dimensión artística y social de la ciudad, publicación del Ministerio de Educación, Cultura y Deporte, Madrid, 2002, p. 58.

24 Portela Sandoval, Francisco, Ibidem.

${ }^{25}$ Limitada a la efigie del homenajeado o extendida a algunos motivos simbólicos o a lo meramente ornamental, que es la preferida para ser instalada en la casa de un determinado personaje o en el escenario de un singular acontecimiento histórico.

${ }^{26}$ GAYA NuÑo, Antonio, "La escultura ecuestre en el arte barroco", revista Goya, noviembre-diciembre 1958, n. ${ }^{\circ} 27$, p. 151.

Arch. esp. arte, LXXXIv, 333, ENERO-MARZO 2011, 25-40, ISSN: 0004-0428 


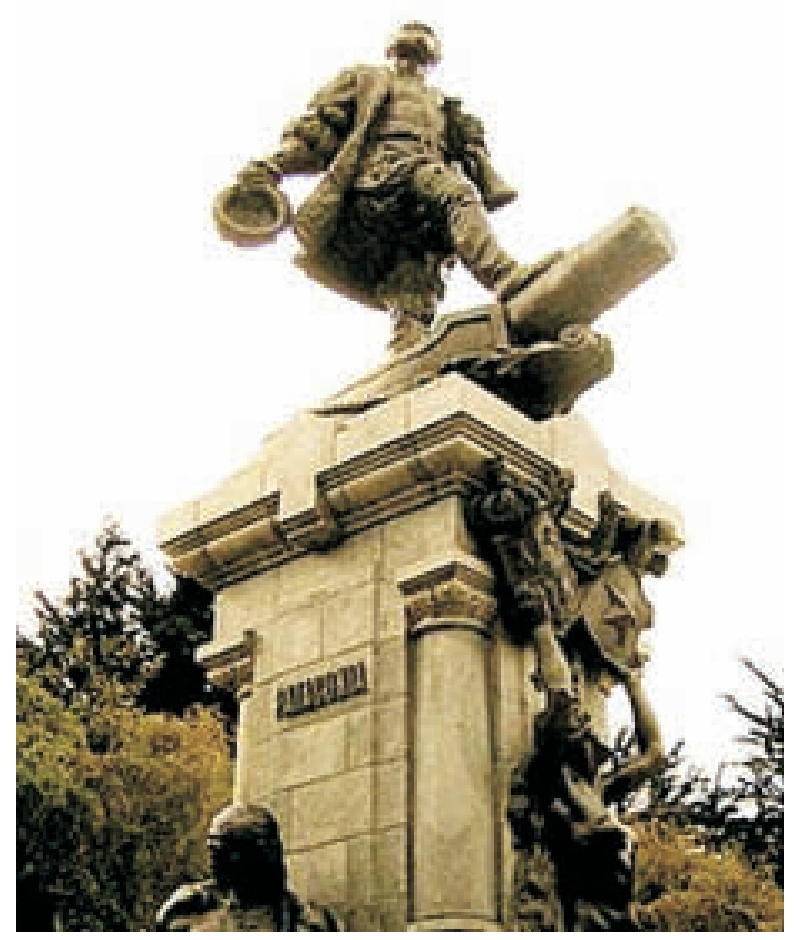

Fig. 7. Guillermo Córdova, Homenaje a Hernando de Magallanes, 1921, Plaza de Armas de Punta Arenas, Chile. concepto de identidad y de la propia concepción simbólica. En una época de escasa iconografía visual, la presencia de monumentos escultóricos, pinturas, y la reproducción de láminas con sucesos históricos, expresaba los conceptos de una pedagogía explícita, a la vez que fortalecía las nociones de historia, patria e identidad. El apogeo monumentalista se dio hacia fines del siglo XIX, hasta la década de los cuarenta de la pasada centuria. El Estado fue el principal promotor de estas obras, aun cuando no el único. En Chile, a modo de ejemplo, la Colonia Francesa donó al país, en 1910, el grupo alegórico ubicado en Santiago frente al Museo de Bellas Artes.

\section{El monumento público: episodios militares en Chile}

El monumento público ha estado en nuestro país fuertemente relacionado con episodios bélicos. No cabe duda que la Independencia y la Guerra del Pacífico, entre otros hechos, señalaron una necesidad de exaltación patriota que dio contenido al discurso literario, pictórico y escultórico de aquella época. La Guerra del Pacífico representó para Chile una victoria y el episodio quedó registrado en varias obras. Una de las esculturas más significativas fue el "Monumento a los héroes de Iquique" (fig. 8), obra encargada a Denis Pierre Puech, en 1886, que contó también con la participación de Virginio Arias. El conjunto escultórico se encuentra en la Plaza Sotomayor, en Valparaíso. El monumento incorpora asimismo las estatuas en bronce (fundidas por Thiebaut Fréres en París) de otros próceres asociados a esa gesta. Es el caso de Ernesto Riquelme, Juan de Dios Aldea -ambas realizadas por Virginio Arias-, Ignacio Serrano y el Marinero Desconocido, estas dos últimas de Puech. José Caroca Laflor (1898-1966), por su parte, realizó también un monumento a los héroes de Iquique, que se ubica en la actualidad en Santiago. Dentro de este recuento no se puede omitir el proyecto de un monumento a los héroes de Iquique encargado al escultor francés Augusto Rodin, quien presentó la obra "Llamado a las Armas", que había sido a la vez presentada al concurso de conmemoración de la guerra FrancoPrusiana. Finalmente emplazada en Francia, en el memorial del campo de Batalla de Verdún en 1922, el original de esta escultura se encuentra en el museo Rodin de París. La copia en bronce que el escultor francés envió a Chile no fue aceptada para el monumento a los héroes de Iquique y se encuentra ubicada en la actualidad en la Avenida Libertad de Viña del Mar. De Rodin encontramos también un proyecto de monumento ecuestre al General Patricio Lynch (fig. 9), héroe de la Guerra del Pacífico, cuya copia $(43 \times 34 \times 16 \mathrm{~cm})$ en bronce se encuentra en el Museo Nacional de Bellas Artes. De Virginio Arias encontramos también una escultura ecuestre de otro de los héroes chilenos de la Guerra del Pacífico, el General Manuel Baquedano (fig. 10).

Arch. esp. arte, LXXXIV, 333, ENERO-MARZO 2011, 25-40, ISSN: 0004-0428 
Otro episodio bélico de la Guerra del Pacífico, el Combate de la Concepción, inspira varios otros conjuntos escultóricos. Entre ellos el monumento realizado por Guillermo Córdova en homenaje al Teniente Luis Cruz Martínez, héroe de la batalla, que se ubica en la ciudad de $\mathrm{Cu}-$ ricó. Rebeca Matte realizó, por su parte, en 1902, la obra "Héroes de la Concepción", que alude al mismo episodio bélico.

Muchas otras obras con temáticas militares se hicieron al margen del monumento público. Entre ellas "El tambor en reposo" (fig. 11) (bronce, $110 \mathrm{~cm} \mathrm{de}$ altura), de José Miguel Blanco, perteneciente a la colección del Museo Nacional de Bellas Artes. Virginio Arias suma aquí también algunas obras; entre ellas la ya comentada obra "El roto chileno", que realizara estando en París en 1882. Los episodios militares y los héroes nacionales dan forma a un modelo potente en la construcción del imaginario cultural del país. Se trata de

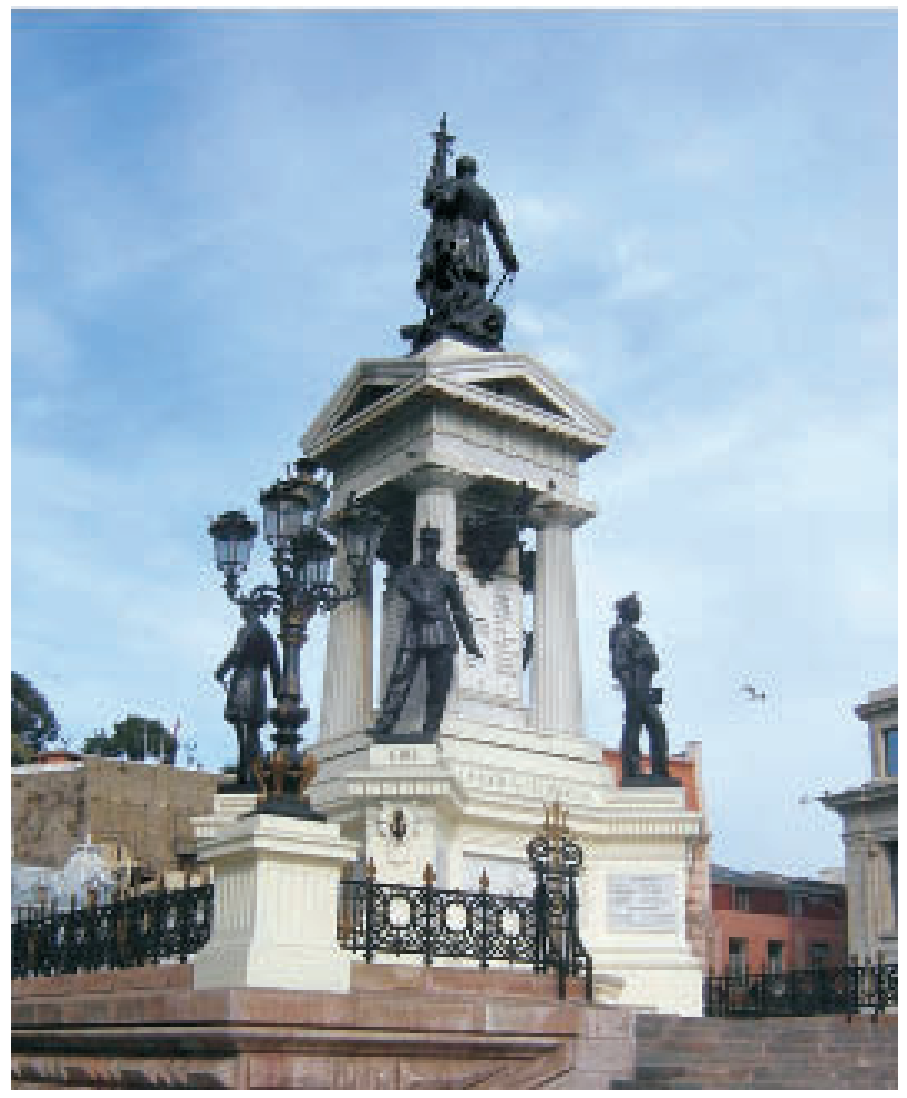

Fig. 8. Denis Pierre Puech, "Monumento a los héroes de Iquique", 1886, Plaza Sotomayor de Valparaíso, Chile. tiva, inserta muchas veces en los ejes de la ciudad, destinada a grabar en la memoria colectiva estos hechos y personajes. Una escultura de exaltación que podría ser parangonada con algunas pinturas realizadas en Chile por José Gil de Castro, Juan Mauricio Rugendas, Tomás Somerscales y Álvaro Casanova Zenteno.

\section{El monumento público: héroes de la sociedad civil}

Surge aquí una interesante tipología de esculturas. La "sedente", a modo de ejemplo, como diría Francisco Portela, parece mostrar al personaje desde una mayor intimidad, en una actitud de reflexión. Este tipo de escultura parece haber quedado reservada para sabios, escritores, benefactores y, en algunos casos, para artistas. Ilustra este tipo de obras el monumento a Andrés Bello, realizado por Nicanor Plaza, ubicado en la actualidad en la Casa Central de la Universidad de Chile. También el "Homenaje a Barros Arana", realizado por Virginio Arias. Las representaciones con "figuras de pie" son también muy utilizadas. Se trata de figuras erguidas, con una mirada perdida en el infinito, concebidas con cierta majestuosidad. Recordamos aquí la escultura del Abate Molina, realizada por Augusto Francois, y el retrato de Diego Portales, del escultor francés Jean Joseph Perraud (1860). En algunas ocasiones se combina en un mismo conjunto la figura de pie con la 


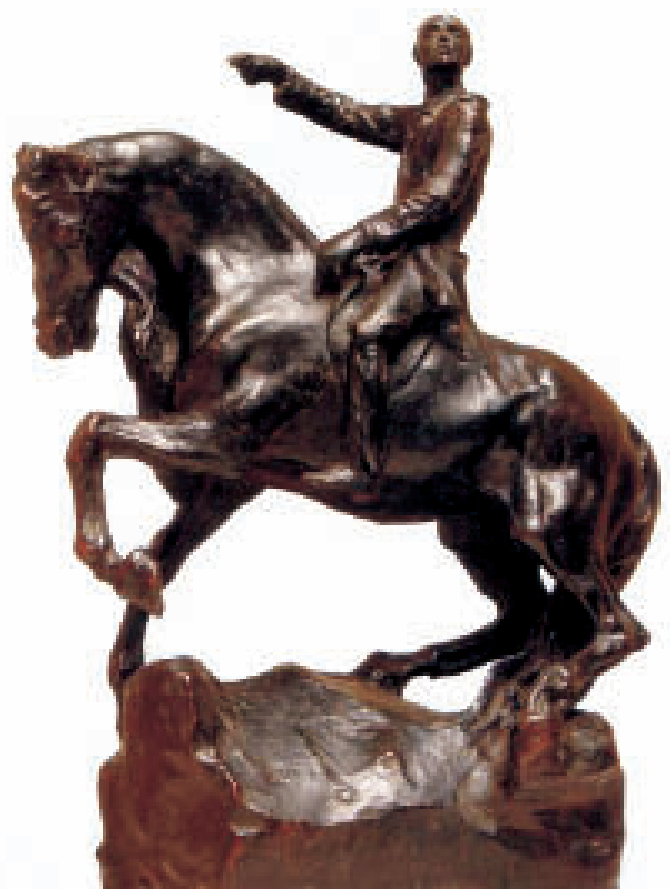

Fig. 9. Augusto Rodin, "Monumento al General Enrique Linch", copia reducida en bronce en el Museo Nacional de Bellas Artes.

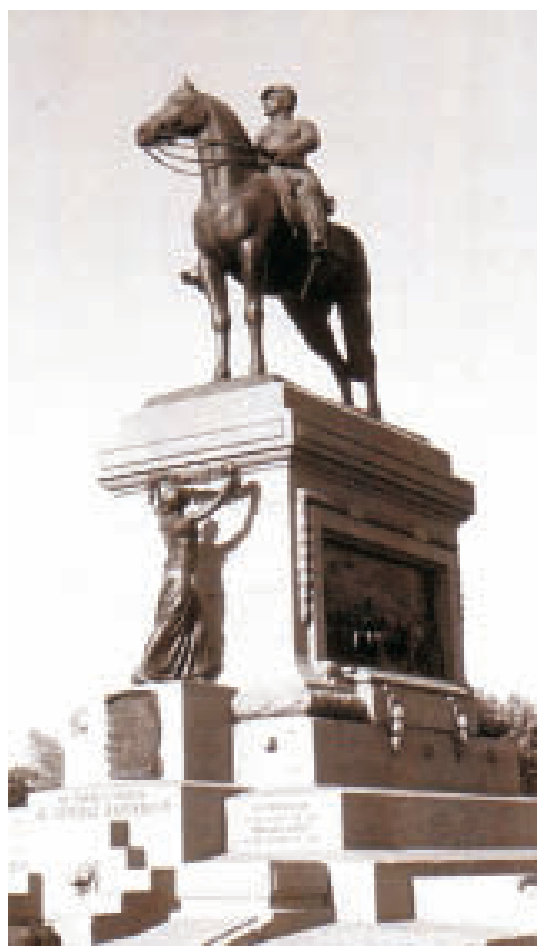

Fig. 10. Virginio Arias, "Monumento al General Manuel Baquedano", emplazada en 1928 en la Plaza Italia de la capital chilena.

sedente. En Santiago, por ejemplo, está el monumento a Manuel Montt y Antonio Varas, realizado por el escultor italiano Ernesto Biondi (1855-1917). Aparece también una interesante tipología de esculturas de cabezas y bustos. Entre ellas, los retratos de Abdón Cifuentes, realizado por José Caroca Laflor, y de José Miguel Infante, cuya autoría corresponde a Nicanor Plaza.

\section{El mundo nativo}

El mundo nativo y la expresión de "lo popular" tuvieron una importante presencia iconográfica en la pintura y escultura chilena durante el siglo XIX. Varios fueron los escultores que cultivaron esta temática. Entre ellos José Miguel Blanco, autor de "Galvarino" (colección Museo Nacional de Bellas Artes) y "El Padre Bartolomé de las Casas amamantado por una india" (fig. 12) (Museo O’Higginiano de Talca), obra esta última que replica la iconografía del tema de la "caridad romana". También encontramos algunas obras de Nicanor Plaza vinculadas al tema aborigen. Entre ellas "Caupolicán", versión chilenizada de "El último mohicano", con una posición y actitud homologable al "David" de Bernini, y "El jugador de chueca", del mismo autor. La identificación de estas obras con los nativos es ambigua y resulta incongruente con los rasgos físicos de los indígenas chilenos. Las plumas, atuendos y ropajes evidencian una actitud hacia una testificación realista, aun cuando no alcanzan a anular del todo la huella del arquetipo clasicista. De Virginio Arias tenemos también la obra "Madre araucana" (Museo Nacional de Bellas Artes). 


\section{Mitología y referencias simbólicas al mundo clásico}

El modelo clásico fue el punto de encuentro y el ordenador estético en la obra de algunos artistas nacionales. Un paradigma cuyas raíces históricas las encontramos en la cultura grecolatina y cuyos antecedentes más directos están en la escuela neoclásica, liderada en el terreno de la escultura por Antonio Cánova y el danés Berthel Thorvaldsen. La mitología griega no estuvo ausente en los repertorios temáticos de varios de los escultores chilenos del siglo XIX. Encontramos muchos desnudos, masculinos y femeninos, con una iconografía pensada en el panteón heleno. Nicanor Plaza, a modo de ejemplo, representa el mito de la "Quimera", en una obra de igual nombre, perteneciente a la colección del Museo Nacional de Bellas Artes. En esta obra el artista releva la sensualidad femenina y no la encarnación del animal fantástico que describe la mitología. Sobre esta obra Miguel Luis Rocuant señaló: "¿Quién no se ha detenido ante lo leve y puro de esta piedra de ensueño?"27. Se trata de una hermosa doncella con alas y cola de serpiente. Ilustran también este concepto las alegorías "Prólogo" y "Epílogo", del mismo autor, ubicadas en el Teatro Municipal de Santiago.

Otra obra, "Hoja de Laurel" de Virginio Arias, rememora a la Afrodita Cnidia de Praxíteles. El grupo de "Dafne y Cloe", de este mismo autor, dice relación con una novela pastoril de Longo de Lesbos, de indudable

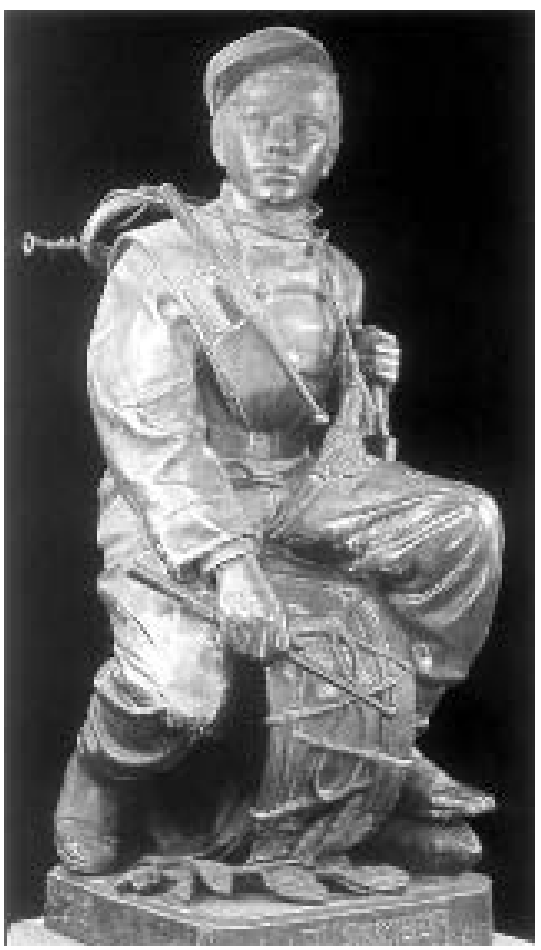

Fig. 11. José Miguel Blanco, "El tambor en reposo", 1884, Museo Nacional de Bellas Artes, Santiago de Chile. débito clasicista. En este concepto podemos situar también la obra de Carlos Lagarrigue conocida como "Giotto", que recuerda a "El espinario" helenístico de la Escuela de Atenas. En el frontón del Museo Nacional de Bellas Artes, Guillermo Córdova nos muestra un conjunto escultórico, Pegaso incluido, con una serie de personajes del panteón pagano. En otro monumento escultórico, donado por la Colonia Francesa en 1910, de este mismo autor, aparece como motivo central una Niké, como expresión alegórica de la victoria. El mito de Ícaro y Dédalo lo encontramos en la obra "Unidos en la gloria y en la muerte", de Rebeca Matte, en el frontis del Museo Nacional de Bellas Artes. De esta artista encontramos dos obras más con esta temática "La ninfa Eco" y el "Horacio". Como se ve, el mundo clásico y la mitología estuvieron presentes en el imaginario de los escultores nacionales durante la etapa de la gestación de la escultura en el país. Estos repertorios iconográficos vienen con la instalación de los primeros conceptos de enseñanza de la disciplina en el país y se refuerzan, posteriormente, en los estudios que realizan en Europa los escultores nacionales. Un capítulo aparte podría escribirse a partir de las numerosas figuras alegóricas fundidas en metal que se emplazaron en las ciudades. El emergente poder político y social tomó la iconografía clásica para glorificar la república y transmitir su discurso progresista ${ }^{28}$.

\footnotetext{
27 Rocuant, Miguel Luis, Las blancuras sagradas, Ediciones Rivadeneyra, Madrid, España, 1921, p. 31.

${ }^{28}$ Fueron frecuentes las imágenes de Mercurio, Diana la cazadora, Neptuno, Apolo, alegorías a la Libertad, ninfas, ateneas, animales y aves (leones, águilas y cóndores), florones, alegorías, entre otros.
} 


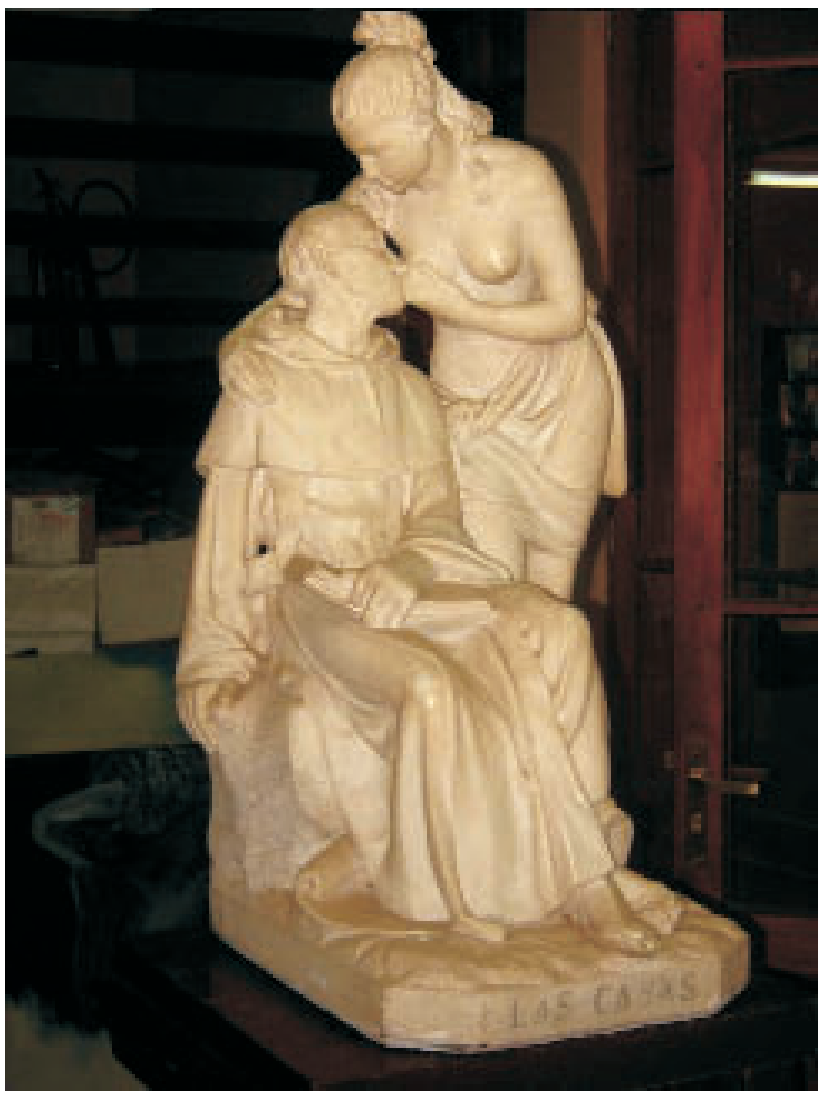

Fig. 12. José Miguel Blanco, "El padre Bartolomé de las Casas amamantado por una india", Museo O’Higginiano de Talca, Chile.

lico del país se encuentra absolutamente debilitado. Su último estertor se da en la gran Exposición de 1910, con la que se celebra en Chile el primer Centenario de la Independencia. De ahí comienzan a gestarse otras miradas y conceptos estéticos que operan sobre las representaciones simbólicas de nuestro imaginario social.

Fecha de recepción: 19-VIII-2009

Fecha de aceptación: 18-XI-2009

\section{El mundo popular}

Los personajes anónimos también tienen representación en la escultura. En los escultores de transición de siglo, más cercanos al debate social y a la sensibilidad realista romántica, comienzan a tomar fuerza estos temas. Es el caso de Ernesto Concha (18751911) con sus obras "Miseria" (fig. 13) y "El avaro"; Simón González, con sus niños y mendigos, y Rebeca Matte con obras tales como "Duro Invierno". Con estos autores y obras la escultura chilena se aleja del clasicismo alegórico, para ir hacia una estética más de compromiso y sensibilidad social.

En los inicios del siglo XX el modelo clásico instalado en la Escuela de Bellas Artes y en el imaginario simbó-

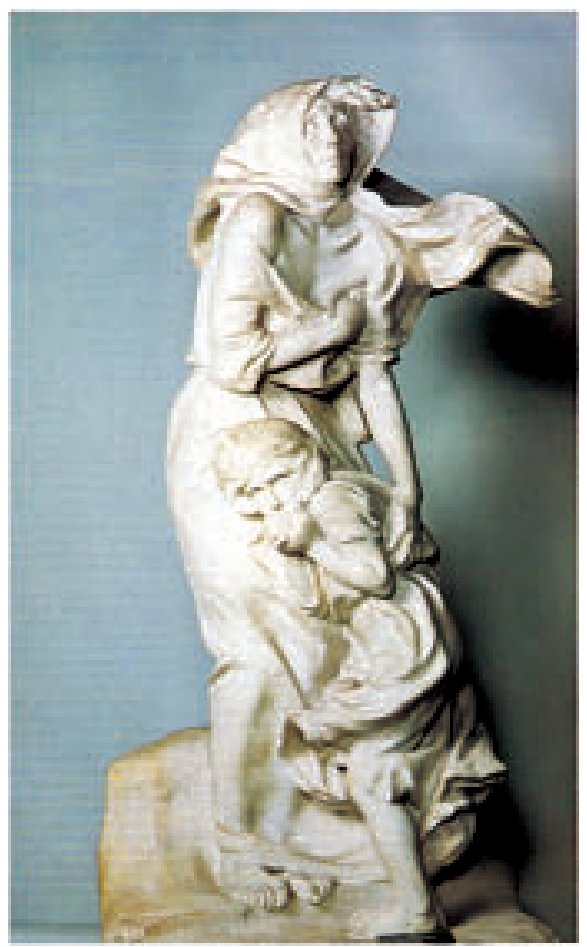

Fig. 13. Ernesto Concha, "La miseria", 1908, Museo Nacional de Bellas Artes, Santiago de Chile. 